\section{Wittgensteins billeder}

Peter K. Westergaard: Ludwig Wittgenstein, Forlaget Slagmark, Århus 2000, 423 sider, 225 kr.

"Bogenerenudførligintroduktion til den østrigske filosof Ludwig Wittgensteins(1889-1951)sprogfilosofiskeogreligionsfilosofisketænkning" - hedder det i den pressemeddelelse, som forlaget Slagmark harudsendti forbindelsemedudgivelsenaf Westergaardsbog.Jeganførerpressemeddelelse fordi jeg har tænkt en del over, hvordanmankankarakterisere,hvad bøger “er", hvad den gårud på, hvem den henvender sig til, hvad den vil, hvaddenkanosv.Medandreord:hvilken genre, hører den til? Og her er pressemeddelelsenbrugbar,fordiden er så forkert. Det er forholdsvist let at sige, hvad bogen ikke er (omend derogsåherermangemuligheder).En af de ting den ikke er er en introduktion. Det er der en række grunde til. Grunde,derhverisærertilstrækkelige, mensomsammenlagthinsidesenhver tvivl gør, at bogen ikke kan kaldes en introduktion: dens omfang (423 sider), ingen systematisk indføring $i$ eller systematisk kommentar til hele Wittgensteins filosofi, men derimod perioderne 1913-16 og 1936-39; der er stortsetingenreferencertilandrefilosoffer eller til, hvad det var for et filosofiskproblemlandskabWittgenstein stødte ind $i$, og som han begyndte at navigerei;tekstenermegetomstændelig,bl.a.pågrundaf densallestedsnærværendereferencertilNachlass'vældaf tekstvarianter-herunderopstillingaf konkordansskemaer,somingennybegynder kan stille noget op med-eller børbrugetidpå;derermeget,megetfå biografiskeoplysninger(ogiWittgen- steins tilfælde er de ikke bare alment underholdende, men også teoretisk relevante,f.eks.ikkemindstiforhold til de to ekstentielle kriser som de to perioderrummer).Altsåingenintroduktion.

Men hvad er bogen så? Den erengennemgang-megetomhyggeligoggrundig-af to (måskedevigtigste)perioderiWittgensteinslivogisær i hans filosofisk produktive tid, hvor deri disse perioder fokuseres dels på sprogfilosofienogdelspåovervejelser overetisk-religiøseproblemstillinger. Detforbindendeelleroverordnedeer ibeggetilfælde(omendpåmegetforskellig vis) billedbegrebet.

Westergaard har bl.a. og ikke mindstvigtigthaftadgangtilogarbejdetmedWittgensteinarkivetiBergen. Herharmanientiårigperiodeopbygget en komplet elektronisk udgave af, hvad der har kunnet opdrives af Wittgensteinmanuskripter-vist nok omkring 30.000 sider-som er skrevet udogparallelthermedaffotograferet. Tilligeerdermegeteffektivesøgeredskaber. Arbejdet er lige afsluttet (og vilblivetilgængeligtigennem $O x$ ford UniversityPress).Wittgensteinarkivet iBergenskabernyemulighederiWittgensteinforskningen.IWittgensteins tilfælde er et offentligt tilgængeligt arkivalaBergensextremtvigtigt,ikke mindst på baggrund af, at Wittgensteinselv(stortset)kunudgavetværk, nemligTractatus.Alleandreudgivne værker er redigeret af udgiverne. $\mathrm{Og}$ medredigeretmenesdervirkeligredigeret,forWittgensteinsarbejdsmåde varigennemgribendeforstandpræget af rettelser, overstregninger,indklip, omorganiseringosv.-heletidenvarde tekster, han selv såi et udgivelsesperspektiv, under forandring og i bevægelse. Noget af det samme gør sig 
gældendemeddemanuskripter, han ikkebetragtedesomudgivelsesorienterede.

Westergaards arbejde er en frugt af især dette arkiv, der om man så må sige ikke gør detlettere af være Wittgensteinforsker.Måskemereinteressant og udæskende, men ikke lettere.Tilligevilarkivetstillestorekrav til forskerens - filosofiske - proportionssans.Hermedtænkerjegpå,atder nu er rig og forførende lejlighed til at løbevildblandttræerneudenatkunne se nogen som helst skov længere.

Bogens første del - de første 200 sider-handler om Wittgensteins arbejder fra 1913 til 1919. Altså den periode,dermunderudiudgivelsenaf Tractatus.

Tractatusstodogstårformange i samtiden og nutiden som et fascinerendeorakelopusmedentvingende dybdeilapidariskesætninger,tilsyneladendebyggetopsometlogiskdeduktivt system - men for de fleste uden sammenhæng og nærmest uforståeligt. Man fornemmer dog, at der er tale om i hvert fald følgende komplekser:sprogfilosofiskerefleksioner, logiskeogontologiskeudsagnogetiskreligiøseudsagnplusmystik.Problemeterikkemindst,hvordandehænger sammen - hvis de gør det. I lange strækningerminderTractatusmereom poesiend filosofi(hvadWittgenstein næppe ville opfatte som en indvending).

Detrådesderinogengradbod påmedWestergaardsanalyse, dervel er et af de hidtil mest minutiøse desangående.Detgennemgående tema erbilledteorier(sombogensundertitel lyder: "Hele billedligheden i vor udtryksmåde").Medbilledteorimenes, at sproget(dersomdet anvendeskorrekt, og det vil i perioden frem til
Tractatussige,naturvidenskabeligteller naturvidenskabeligtanalogt)erenlingvistisk-symbolskafbildningaf kendsgerningeriverden, hvorgrunddogmet er, atsprogetogverdenharsammelogiskeform, hvorfor sproget kan afbilde verden.

Dererenrækkeklarificeringer iWestergaardsarbejde:dateringenaf billedteoriens fremkomst $i$ Wittgensteinstankerum(udenatderdoggøres noget forsøg på at afdække, hvorhan kunneværeinspireretfra); afdækningenaf opkomstenaf denetisk-religiøse dimension på baggrund af Wittgensteins eksistentielle krise i 1916. Og så forsøg på at samtænke disse to momenter.Hererdermegetinformativtomdetuudsigeligeogdetmystiske. EtcentraltpunkterWestergaardsinsisteringpå,atdeetisk-religiøseudsagn samtudsagneneomdetmystiske(og andrefænomenermedfamilielighed) iTractatusikkeumiddelbartbørinterpreterespåbaggrundaf optegnelserne idagbøgerne(hvaddersidendisseblev offentliggjortharværetnærliggende, daTractatusmildesttalterordknapher). Westergaardviserderimod, atdersker enrækkeændringerogforskydninger undervejsfradagbogsoptegnelsernetil Tractatus.(Enlillebemærkningiforbifarten:atWestergaardcitererdagbogsoptegnelserne på engelsk er mig en gåde;bådedealmindeligeogdehemmelige var skrevet på tysk).

Arbejdet er meget omhyggeligt - ja til tider så omhyggeligt, at det for en læser kan være vanskeligt at følge med, især fordi billedet flimrer på grund af de mange henvisninger til Nachlass, som man jo ikke har for hånden, mens manlæser. Problemet ermåske objektivt eller uundgåeligt: Westergaard kan ikke dokumentere uden at referere, men det kan virke 
trættende og distraherende.

Arbejdeterdogstyret,ogyderst informativt, dersom man på forhånd erinde i, hvad det drejersig om-altså har etvist, helstikke ringe, kendskab til Wittgenstein. Om det lykkes at få sprogfilosofien til at hænge sammen meddetetisk-religiøsekanderstilles spørgsmåltil.Mendeterikkeenkritik af Westergaard, for han forsøger virkeligatbyggebro-ogviser, atdetsker medabsolutfodfæsteiWittgensteins efterladte papireroghans selvforståelse.Westergaardcitererenoptegnelse (fra 6.7.1916), hvor det lyder: "Habe vielüberallesMöglichenachgedacht, kann aber merkwürdigerweise nicht dieVerbindungmitmeinenmathematischenGedankengängenherstellen". Denforbindelse, detherdrejersigom er forbindelsen mellem de etisk-religiøse tanker/udsagn og så de sprogfilosofiske. Dagen efter lyder det i en optegnelse:“AberdieVerbindungwird hergestelltwerden!".Pågrundaf den meget rigoristiske, kantede og til det yderstemeningsreduktivesprogteorier forbindelsen, der oprettes hele vejen igennem egentlig en art via negationis-forbindelse,idetkoblingspunkterne bliver"detmystiske",det"uudsigelige" osv. som er indekser på det forhold Wittgenstein omtaler i et brev til en potentieludgiveraf'Tractatus, nemligat han har skrevet en bog, hvor det vigtigste erdet, somikke ståriden. Hele Tractatusprojektet er en stor performativselvmodsigelse.Måskeerdetdet, som til syvende og sidst giver værket dybde, men det er også med til at gøredethermetiskogmegetvanskeligtatforstå.Samtidenslogikfetichister betragtededenetisk-religiøsedimension som et personligt, egentlig filosofiskuvedkommende,vedhæng.Men sagen er, at heller ikke den rent logi- skesprogforståelseogdekriterier,den hvilerpå,undgåratværeperformativt selvmodsigende.Ifølgeoverleveringen skulle den italienske økonom Sraffa (der var i Cambridge) efter Wittgensteins tilbagekomst 11929 have gjort hamopmærksompå,atdervaretstort problem med hans billedteori: den kunnenemligikkeviseselveafbildningen,menkundetafbillede.Hvilketer korrekt,meniogforsigbloten anden mådeatudtrykkehelekonstruktionens mærkværdighed.Fordersomdetskulle gælde,hvaddersigesombilledteorien, såkunnedetikkesiges.Eller,hvis Tractatus'sprogfilosofiskepåstandeerrigtige, såkandeikkesiges, fordiethvert udsagn om et udsagn på forhånd er gjort meningsløst.

Derertaleometrespektaftvingendeimmannentrekonstruktionsforsøg hos Westergaard. Og det vises, hvilkespring,deroptræder.Dererogså mikrologiske overvejelser over eventuelleteorikonsekvenserpåbaggrund af små terminologiskeforandringer, f.eks. mellembrugen af "hemmelighedsfuld" contra "mystisk". Somme tiderharjegdogunderlæsningenhaft enfornemmelseaf, at detkunnehave været rart, dersom Westergaard en gang imellem var stoppet op for at giveenoverordnetfremstillingogtolkning. Nu følger vi forskydninger og ændringer så tæt, at det ofte er som om det er forskydningerne i sig selv, somblivertolkningsafgørende.Deter næsten som om Wittgensteins afsky for metarefleksion har smittet af på Westergaardsfremstilling.Detgælder især afdækningen af den første periode fra 1913 til 1919, men ikke kun.

Anden delen af bogen - de sidste 200 sider - omhandler som nævnt perioden 1936 til 1939, en peri- 
ode, hvor Wittgenstein i lange tidsrum opholder sig i hytten i Skjoldeni Norge oghvorhans senfilosofierved atmodne.Medsenfilosofimenesførst ogfremmesthansbrudmed Tractatus' sprogopfattelseogfremkomstenaf en praxis-semantisk teori for sprog.

Westergaardforfølgerfirespor idenneperiode:ensprogfilosofisk,en antropologisk,enbilledteoretiskogen religionsfilosofisk (s. 207).

Densprogfilosofiskevending erkendt, hvad Westergaard tilføjer er en redegørelse for de mange små ryk fra opfattelsen af sprog som lingvistiskrepræsentation, hvorlogikkener semantikkensgrund(Tractatus)over opfattelsen af sprog som kalkule til forståelsen af sprog som brug, hvorveddagligsprogetkommertilatspille encentralrolle.Detopdagesogunderstreges nu - med et udtryk lånt fra Løgstrup - at ordene har vidde og prægnans, og at det erikraft heraf og ikke(længere)somoppositionhertil, at de har mening. Der er oplysende afdækningeraf mellemregningernei denne udvikling hos Wittgenstein.

Merenyterderipåpegningen af det antropologiske træk. Hermed menes, at sprog er et træk ved den menneskeligeorganisme-overdisponeretsagt:sprogbrugerfunderetiden menneskeligeorganismeogdennestilegnelseaf sprog. Trækketerantydeti dentidligereperiode,mennukommer der mere kød på sagen. Westergaard giver en klar redegørelse for, hvilke pointer og hvilke problemer, der er forbundethermed:pointen erbl.a.at en platonisk sprogforståelse nu ikke bare kan afvises, tillige kan dens forførelseskraftafdækkes.Problemerne kommer derimod af, at vi bevæger os på en grænse, idet der sammen med denantropologiskeinsisteringmarke- res, at der ikke kan være tale om en referencetilen"ren"sproguafhængig biologisk natur. Der er her tale om noget der udelukkende refererer " $t$ il en antropologisk fond af visse førsprogligehandlingsabiliteter,ellerlad ossigeetspektrumaf visseprototypiskeudtryksformer-urformer(...),skemaer $(, . .$.$) - der også er at betragte$ som et repertoire af delvis diffuse rudimentærereaktionstilbøjelighederdergennemafretningførstsubstitueresaf simplelingvistiskeudsagn,som siden danner grundlag for de mere kompleksesproganvendelsessammenhænge" (s.322). Sådanlyder Westergaardsforsigtigemarkering.Hanhar uden tvivl fat i et spor, som er til stede hos Wittgenstein, og som vel er vigtigt,mensomdetpådenandensideer vanskeligt at stille noget op med. For en ting er, at det måske med plausibilitetkanhævdes, at den menneskeligesprogbrughardennebaseidiffuse rudimentærereaktionstilbøjeligheder, noget andet er, at vi fornemlig aldrig vilkunneafdækketransmissionenog transformationen af disse frem til “udviklet" sprogbrug - ikke mindst fordi den faktiske sprogindlæring jo altid vil foregå i et sprogmiljø, hvor hovedpartenaf detilstedeværendealtid alleredeharetudvikletsprog. Mendet erikke et problem, som Westergaard kanklandresfor-tværtimoderdeten stor fortjeneste, at han nu har dokumenteret, at sporet findes i Wittgensteinstænkning.Andreharpåståetdet før, men nu er det dokumenteret.

Wittgensteinbrødisenfilosofienmed'Tractatus'sprogopfattelseog densbilledteori.Menogsåisenfilosofienanvendesbilledbegreber. Westergaard spørger nu: er der tale om en videreførelse fra Tractatus? Svaret er selvfølgelignej,fordersomdervartale 
omensådaniurokketbetydning, ville senfilosofienganskeenkeltikkekunne artikuleres-dentractarianskebilledteori ville blokere. Men er der da tale om en helt ny teori ombilleder? Både ja og nej. For visse træk fastholdes - således at mennesket er et billedskabendeogbillederkendendevæsen (dettemomentharrødderidenantropologiskedimension,dersomWestergaardharvistbådegælderiTractatus ogisenfilosfien). Men det afgørende nye er, at billedbegrebet integreres $\mathrm{i}$ den nu nye og overordnede prakseologiskesemantiskeramme.Deterdog nogetaf en tilsnigelsebare atoperere med en størrelse, som kaldes billedbegrebet.ForsomWestergaardmeget omhyggeligtdemonstrerererdertale om en række - ikke til hinanden tilbageførlige-billedformer,f.eks.ikoniske,mentale,partikulærelingivistiske ogkonstitutivelingvistiske.Westergaardskonklusionlyderher, atderertale omenmoderatkontinuitetfraTractatustilsenfilosofien.Billedbegreberne bibeholdes og knyttes til det antropologiske spor, men transformeres $i$ kraftaf,atdeindgårienprakseologisk ramme.Hanunderstregerendvidere, atderhos Wittgenstein(idenperiode hanundersøger)ertaleomenansatsaltsåikkeomnogenfuldtudfoldetog systematiskartikuleretteori.Vel,dette med ansats prægeriøvrigthele senfilosofien.

Midti perioden 1936-39- som i perioden 1913-16 - kom Wittgensteinudiendybeksistentielkrise; hele hans voksne liv var vel en krisesammenhæng, men der er dog perioder, hvordetbrændtemerepåendiandre. Atter betød det, at han begyndte at læsereligiøseteksterogidetheletaget atreflektereoverreligiøsespørgsmål. Menentingerdenneparallel,enanden er, at den nye beskæftigelse med religiøsespørgsmål-imodsætningtilden tidligereperiode-ikkesøgesintegreret idennye teori, somdennetagerformi forarbejdernetillPhilosophischeUntersuchungen.DenyetankerudfoldedeWittgenstein derimod $i$ tre forelæsninger overreligiøstro,somhanholdtiCambridgei1938.Viharkundisseforelæsningeroverleveretgennemdeltageres nedskrivninger,samtfragmentariske optegnelseriNachlass. Westergaard belyserdissetankervedendnuengang (ogdetforekommerikkepåklistret)at sættetankerneirapporttiletbilledbegreb. Det kommer der en fin analyse ud af - hvor hovedsynspunktet er, at religiøssprogbrugiendnuhøjeregrad endandensprogbrugerhenvist tilbilleder. Også disse er integreret $\mathrm{i}$ den prakseologisk-semantiskeramme,dvs. atdeerunderkastettilegnelsesformer -afretning,indøvelseogforklaringersomandresprogformstilegnelser. $\mathrm{Og}$ deres mening er deres brug; de refererer ikke til noget $\mathbf{i}$ den empiriske verden. Og de kan ikke oversættes (her understreger Westergaard med rette, atdenneuoversættelighedogså angår emotioner: religiøse billeder $\mathrm{i}$ sprogbrugladersighverkenoversætte til emotionssprog eller forklare/ legitimereudfraetsådant).MensbilledbegrebetiTractatusafskarreligiøse artikulationer deres betydning, ikke fordidevarprægetaf meningsløshed, menfordideegentligvaruudsigelige, så sker der nu det forbløffende, at det religiøsesprogfaktiskblivereksemplarisksomeksempelpåetbilledbegreb in actu.

Som det blev sagt i begyndelsen af denne anmeldelse er Westergaards bog ikke nogen introduktion. Den er derimod en yderst omhyggelig og meget immanent rekonstruktion af 
Wittgensteins tænkning $i$ to af de mest afgørende perioder i hans (filosofiske) liv. Der fokuseres på sprogfilosofierne (hvad der er selvfølgeligt) og etisk-religiøse forestillingskomplekser (hvad der er mindre selvfølgeligt) og så billedbegrebets opkomst og fastholdelse (hvad der er er yderst usædvanligt). Der er mange afdækninger, som må have relevans for og $\mathrm{i}$ Wittgensteinforskningen. Det er ikke helt ringe (for at sige det på jysk), at vi nu på dansk har fået et så vægtigt bidrag, der går i clinch med Wittgensteins Nachlass.

Hans-Jørgen Schanz

\section{Marx og fremmedgørel- sen revisited}

Jens Peter Kaj Jensen, Det frie menneske - en bog om fremmedgørelse, frihed og frigørelse, Odense: Odense Universitetsforlag 2000, 239 sider. 248 kr.

At det intellektuelle klima kan ændre sig markant på ganske få årtier ja, nogle gange endda på ganske få år - virker indlysende. Et henkastet blik på den nyeste tids idehistorie rækker, hvis man vil forsikre sig om en sådan påstands banalitet. I 1970'erne kunne man således kun dårligt gennemføre sit studie ved det humanistiske fakultet uden i større eller mindre grad at inddrage en vis grad af venstreradikal, gerne marxistisk, emancipatorisk teori i disse selvsamme studier. Begreber som fremmedgørelse og frigørelse kom i et sådant intellektuelt klima helt naturligt til at stå i centrum. Med 80'erne kom imidlertidig en ny idehistorisk bølge rullende ind over de universitære og intellektuelle miljøer i Danmark (efter i en årrække at have hærget under sydligere himmelstrøg) og begreber som de førnævnte forsvandt med et trylleslag fra dagsordenen for at blive erstattet med andre begreber, der bedre kunne beskrive la condition postmoderne. Andre begreber, andre sprogspil, kom på mode. Nu står vi så i en tid (og i et intellektuelt miljø), der på mange måder ikke længere kan kaldes postmoderne. En tid, hvor oplysningsfilosofiske begreber og ideer igen vinder indpas (jf. Per Aage Brandts semiotiske korstog, Sokal-affæren). I kølvandet på denne oplysningsfilosofiske strømning kan vi også passende placere den bog som er omdrejningspunkt for denne anmeldelse - Det frie menneske - en bog om fremmedgorelse, fribed og frigorelse af Jens Peter Kaj Jensen (JPKJ), filosof fra Odense Universitet - hvor der uden større besvær, faktisk med stor overbevisningskraft, tages afsæt $\mathrm{i}$ en vis Karl Marx - idehistorisk protagonist af delvis oplysningsfilosofisk observans der ellers til for ganske nylig (og stadig til en vis grad) i de intellektuelle miljøer har været betragtet som en "toten Hund". Dette er i sig selv en begivenhed. At JPKJ samtidig også har begået en særdeles velskrevet og spændende bog skal der her selvfølgelig ikke klages over. Lad os i stedet se lidt nærmere på bogens indholdsmæssige side, hvor der til gengæld - kritikkens natur tro er enkelte klagepunkter.

Kort skitseret er JPKJs projekt i Det frie menneske ... at undersøge den fremmedgørelse som han - i selskab med den unge Marx - mener særligt kendetegner det moderne kapitalistiske samfund og dets produktionsmåde, for i samme åndedrag at undersøge muligheden for menneskets frigørelse fra denne fremmedgørelse, som igen 